\title{
Paleomagnetic study of the Great Foum Zguid dyke (southern Morocco): A positive contact test related to metasomatic processes
}

\author{
P. F. Silva, ${ }^{1,2}$ B. Henry, ${ }^{3}$ F. O. Marques, ${ }^{2}$ P. Madureira, ${ }^{4}$ and J. M. Miranda ${ }^{2}$ \\ Received 21 July 2006; revised 12 September 2006; accepted 4 October 2006; published 1 November 2006.
}

[1] When a paleomagnetic pole is sought for in an igneous body, the host rocks should be subjected to a contact test to assure that the determined paleopole has the age of the intrusion. If the contact test is positive, it precludes the possibility that the measured magnetization is a later effect. Therefore, we investigated the variations of the remanent magnetization along cross-sections of rocks hosting the Foum Zguid dyke (southern Morocco) and the dyke itself. A positive contact test was obtained, but it is mainly related with Chemical/Crystalline Remanent Magnetization due to metasomatic processes in the host-rocks during magma intrusion and cooling, and not only with Thermo-Remanent Magnetization as ordinarily assumed in standard studies. Paleomagnetic data obtained within the dyke then reflect the Earth magnetic field during emplacement of this well-dated (196.9 $\pm 1.8 \mathrm{Ma}$ ) intrusion. Citation: Silva,P.F., B. Henry, F. O. Marques, P. Madureira, and J. M. Miranda (2006), Paleomagnetic study of the Great Foum Zguid dyke (southern Morocco): A positive contact test related to metasomatic processes, Geophys. Res. Lett., 33, L21301, doi:10.1029/2006GL027498.

\section{Introduction}

[2] The thermal remagnetization of host rocks during magma intrusion and cooling enables the use of paleomagnetic "contact test" as a reliable criterion to date the magnetization acquisition obtained for the igneous body itself. To be positive, a contact test needs that the remanent magnetization direction in the host-rocks be different from that within the igneous body, except very close to this body where they are thermally remagnetized by the intrusion [Butler, 1992]. To investigate the implications of thermal and chemical responses of sedimentary rocks that host igneous bodies and hence validate a paleopole, an exhaustive paleomagnetic study was carried out along several crosssections in Foum Zguid dyke (FZD, southern Morocco) and its hosting sedimentary rocks.

[3] A total of 75 igneous samples from the FZD and 34 samples from the host rocks were used in this study (Figure 1). The calculated magnetic declination of the present magnetic pole $\left(3.2^{\circ} \mathrm{W}\right)$ is similar to the results obtained from International Geomagnetic Reference Field Observations (IGRF 2000) for the FZD, indicating no local field deviation. Silva et al. [2004] found that Ti-low

\footnotetext{
${ }^{1}$ Departamento de Engenharia Civil, Instituto Superior Engenharia Lisboa, Lisbon, Portugal.

${ }^{2}$ Instituto Dom Luiz, Universidade de Lisboa, Lisbon, Portugal.

${ }^{3}$ Laboratoire de Paleomagnetism, Institut de Physique du Globe de Paris, Centre National de la Recherche Scientifique, Saint-Maur, France.

${ }^{4}$ Centro de Geofísica, Universidade de Évora, Évora, Portugal.

Copyright 2006 by the American Geophysical Union. 0094-8276/06/2006GL027498
}

titanomagnetite phase with a dominant PSD magnetic grain size is the main magnetic carrier for the FZD. The sedimentary host rocks show fine-grained hematite mostly newly-formed during Fe-metasomatism related to dyke emplacement [Silva et al., 2006]. Hematite content decreases with distance to the dyke margin.

[4] The FZD is a vertical, NE-SW trending mafic dyke that intrudes Precambrian and Palaeozoic rocks of the AntiAtlas belt in southern Morocco [e.g., Leblanc, 1974] (Figure 1). It is ca. $200 \mathrm{~km}$ long, with an average thickness of $120 \mathrm{~m}$. No evidence of post-emplacement reactivation has been found [Marcais and Choubert, 1956]. The FZD belongs to the Central Atlantic Magmatic Province (CAMP), which is related to the opening of the Central Atlantic during Pangea break-up [e.g., May, 1971; Sebai et al., 1991]. It shows a transition from dolerite at the margins to granophyre at the center. The main mineral association is composed by plagioclase + clinopyroxene + pigeonite with accessory amounts of magnetite \pm ilmenite \pm hornblende \pm biotite \pm apatite \pm quartz \pm sulphide grains [Aarab et al., 1994].

[5] For the FZD, radiometric dating, using K/Ar on whole rock, yielded ages between 186 and $191 \mathrm{Ma}$ [Hailwood and Mitchell, 1971]. This age has been specified by ${ }^{40} \mathrm{Ar}{ }^{39} \operatorname{Ar}[$ Sebai et al., 1991] at $196.9 \pm 1.8 \mathrm{Ma}$. Hailwood and Mitchell [1971] and from paleomagnetic works within the igneous domains found for FZD only normal polarity, which suggests a short duration of the magmatic activity.

\section{Paleomagnetic Study}

\subsection{Laboratory Procedures}

[6] Paleomagnetic measurements were performed in the IPGP Laboratory at Saint Maur. Demagnetization of pilot samples revealed better results using thermal than alternating field (AF) treatments, hence thermal demagnetization was preferred. Magnetization was measured with JR-4 and JR-5 magnetometers (AGICO, Brno). Samples were maintained in a zero magnetic field shield before Natural Remanent Magnetization (NRM) measurements and also during all the demagnetization procedures. Paleomagnetic directions of samples were obtained from linear segments on the Zijderveld plot [Kirschvink, 1980]. Fisher [1953] statistics was used for mean direction determinations.

\subsection{Paleomagnetic Data}

\subsubsection{Sedimentary Host-Rocks}

[7] The analyzed sedimentary rocks belong to 4 crosssections, one across the SE margin of the thick $(\sim 120 \mathrm{~m})$ FZD at FZ8, and three across the margins of two minor dykes at FZ11 (FZD11A $\sim 2.5$ and FZD11B $\sim 13.5 \mathrm{~m}$ thick). At FZ8, host-rocks are pelites and fine-grained quartzites, while at FZ11 they are fine-grained quartz- 


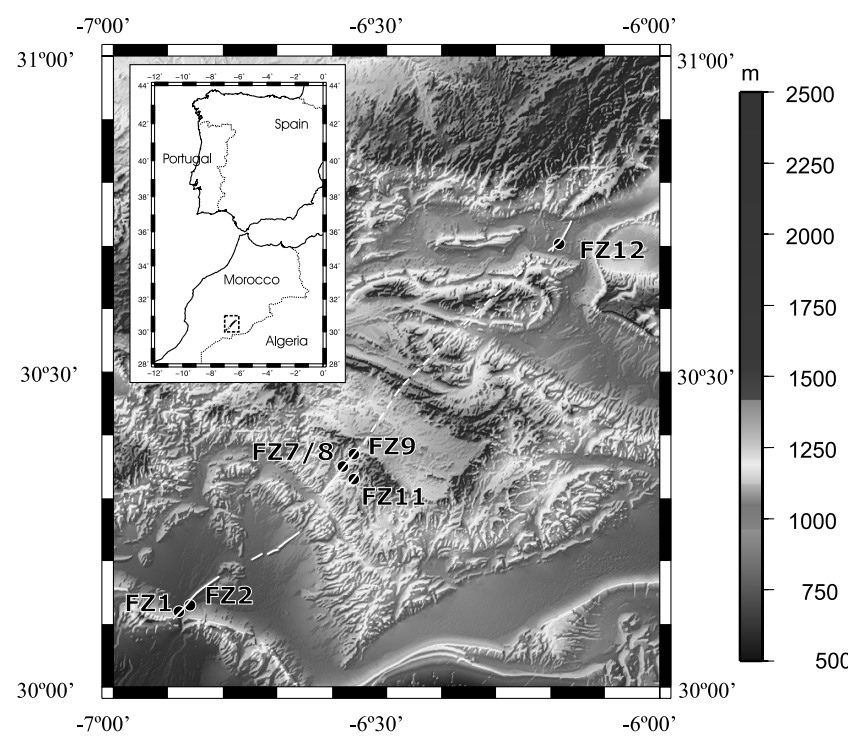

Figure 1. Geographical location of the study area. White solid lines mark dyke outcrops and white dashed lines indicate possible outcrop. wackes and greywackes. These rocks belong to the Adoudounian series, close to the southern limit of the Bou-Azzer El Graara window in the Central Anti-Atlas Mountains [e.g., Leblanc, 1974]. For these outcrops, Silva et al. [2006] distinguished three groups of samples according to Fe-metasomatism intensity:

[8] 1. Group A corresponds to the sedimentary rocks strongly affected by Fe-metasomatism from FZ8 and FZ11. It includes all the FZ8 samples (called here FZ8SM) and, for FZ11, only those located at less than $1.2 \mathrm{~m}$ from the SE margin of the largest dyke FZ11B (FZ11SM). One of the magnetization components is demagnetized at temperatures around $570^{\circ} \mathrm{C}$ (at FZ11, and only close to the dyke at FZ8), while the other ones demagnetize at temperatures around $610-620^{\circ} \mathrm{C}$ (only at FZ8) and between $650-670^{\circ} \mathrm{C}$ (Figure 2a). For each sample, the remanence direction remains stable during all the thermal demagnetization steps, accurately defining the direction of a single high-stability Characteristic Remanent Magnetization (ChRM), as it can be also observed from Zijderveld diagrams (Figure 2a). The ChRM for both FZ8 and FZ11 samples of this Group A shows neighboring directions, with a NW declination and positive inclination (Figures 3a and 3b). However, although

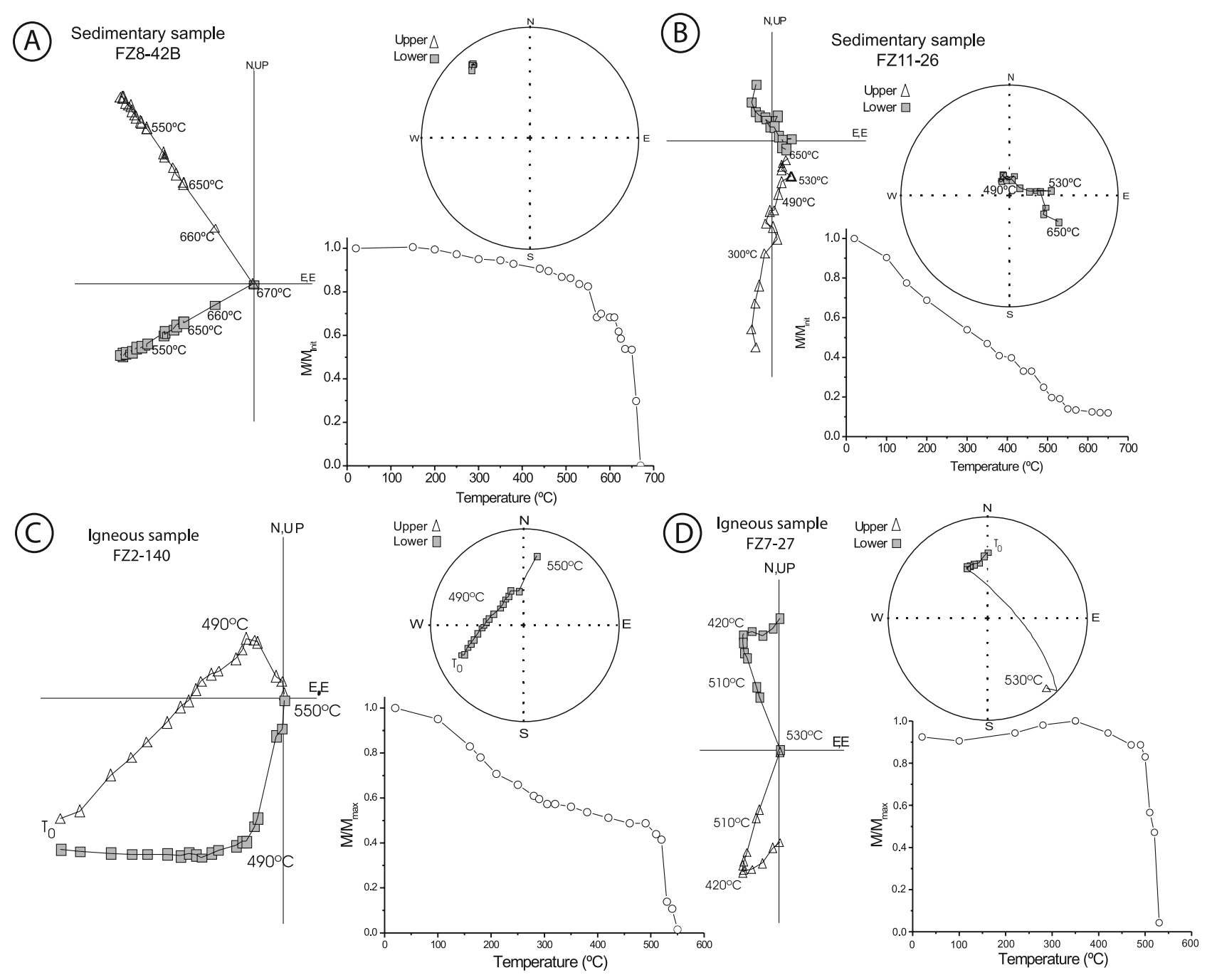

Figure 2. Evolution of intensity and direction of the remanent magnetization of (a and b) sedimentary and ( $c$ and $d)$ igneous rocks during thermal demagnetization procedures. 


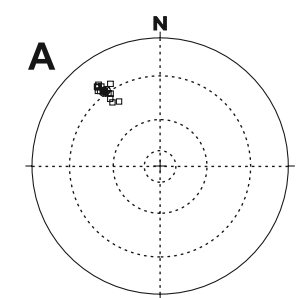

$\mathrm{D}=-39.9^{\circ} ; \mathrm{I}=28.5^{\circ}$

$\mathrm{N}=13 ; \mathrm{k}=157 ; \alpha_{95}=3.1^{\circ}$

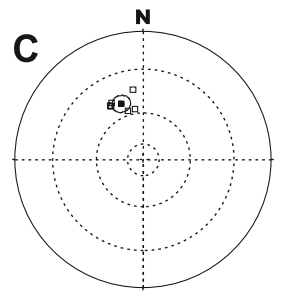

$\mathrm{D}=-23.2^{\circ} ; \mathrm{I}=40.6^{\circ}$

$\mathrm{N}=6 ; \mathrm{k}=106 ; \alpha_{95}=4.8^{\circ}$

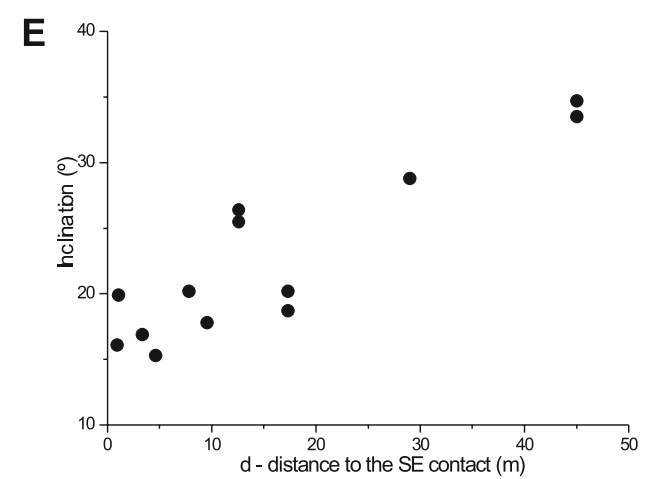

Figure 3. Lower hemisphere stereographic projections of paleomagnetic directions for host rock. Open squares for directions and full symbols for mean ChRM ( $D-$ declination; $I$ - inclination) with confidence zone $\alpha_{95} . \mathrm{N}$ is total of samples and $k$ the precision parameter. (a) ChRM at FZ8 (group A), (b) high-stability component of metasomatized samples from FZ11 - FZ11SM (group A), (c) sediments remagnetized from FZ11 - FZ11SR (group B), (d) sediments from FZ11 - FZ11SD (group C), and (e) inclination of ChRM for sedimentary rocks at FZ8 versus distance from SE contact with dyke.

the Fisher statistics analysis corroborates a good accuracy for ChRM in both sites, it is possible to identify a gradual variation of inclination related to dyke distance for FZ8SM samples (total variation of about $20^{\circ}$, see Figure $3 \mathrm{e}$ ). Plunge variations occur for a declination with an azimuth subperpendicular to the dyke trend. Lower plunges are obtained for the samples closest to the contact. The ChRM for samples the farthest from the contact shows an inclination similar to that for samples of the dyke itself. Interestingly, this evolution does not correspond to a dip variation of bedding in the sedimentary rocks. The mean NRM intensity [Silva et al., 2006] is high for sediments: 1.83 and $0.53 \mathrm{~A} / \mathrm{m}$ for FZ8 and FZ11, respectively. For FZ8, the weakest intensity (mean $0.69 \mathrm{~A} / \mathrm{m}$ ) corresponds to the two samples the farthest from the dyke. The difference in mean susceptibility between the two sites (ranging between 0.12 $0.23 \times 10^{-3}$ SI for FZ8 and between $0.08-0.55 \times$
$10^{-3} \mathrm{SI}$ for FZ11) is likely related to the difference in initial sedimentary rock composition.

[9] 2. Group B includes sedimentary rocks mildly affected by Fe-metasomatism, corresponding to samples located at intermediate distances from the dyke contacts (FZ11SR). Samples have hematite as the main magnetic carrier, deduced from the abrupt decrease of remanence for temperatures between 650 and $670^{\circ} \mathrm{C}$. However, samples of this group also show a decrease in magnetization above $570^{\circ} \mathrm{C}$. Zijderveld diagrams mainly show a single linear component crosscutting the origin (ChRM). A weak component for low unblocking temperature is probably related to a viscous overprint. The ChRM of samples from this group has a NW declination with a positive inclination (Figure 3c). The NRM intensity (mean $0.18 \mathrm{~A} / \mathrm{m}$ ) is always lower than for group A, or even much lower (mean $0.007 \mathrm{~A} / \mathrm{m}$ ) for the two samples of group B closest to group C samples.

[10] 3. Group $\mathrm{C}$ comprises the sedimentary rocks the farthest located from the dykes at FZ11, which are apparently not affected by Fe-metasomatism (FZ11SD). Samples mostly loose more than $50 \%$ of their NRM after thermal treatment at $250^{\circ} \mathrm{C}$ (Figure 2b). For temperatures up to $650-670^{\circ} \mathrm{C}$, the decrease in magnetization is relatively regular. The remanence direction migrates along great circles during demagnetization, as can be observed from the Schmidt projection. However, on the Zijderveld diagram, a component can be well defined from thermal steps up to $630-650^{\circ} \mathrm{C}$. This component is not a ChRM because another higher temperature component clearly exists, which could not be isolated because of its very weak intensity and the fact that it is defined for a too small temperature interval. The mean direction of the main component is statistically different from that of the ChRM of the samples from the intermediate group (angular difference $31.7^{\circ}$ for a critical angle of $12.1^{\circ}$ - test used by Mc Fadden and McElhinny [1990]), and it corresponds to much more scattered directions (Figure 3d). The NRM (mean $0.005 \mathrm{~A} / \mathrm{m}$ ) is much lower than for groups A and B.

\subsubsection{Igneous Rocks}

[11] The samples were mainly collected at the margin of the thick FZD, with dolerite facies. They have maximum blocking temperatures ranging between 500 and $550^{\circ} \mathrm{C}$ (Figures $2 \mathrm{c}$ and $2 \mathrm{~d}$ ), in agreement with the Ti-poor titanomagnetite found as the main magnetization carrier [Silva et al., 2004]. However, the evolution of the magnetization during thermal demagnetization has significant differences among the analyzed samples. Most samples show a gradual decrease of magnetization up to temperatures between 470 and $490^{\circ} \mathrm{C}$, with the remaining signal $(25$ to $70 \%$ of the NRM) vanishing during a final and sharp drop for temperatures between 500 and $550^{\circ} \mathrm{C}$. The remaining samples loose most of the NRM (60 to 90\%) for temperatures between 250 and $300^{\circ} \mathrm{C}$, with the remaining signal gradually vanishing towards temperatures between 510 and $550^{\circ} \mathrm{C}$.

[12] The directional analyzes using the Zijderveld diagrams often point to the presence of several components. One of them is frequently obtained for temperatures that range between $100^{\circ} \mathrm{C}$ and $250-300^{\circ} \mathrm{C}$. As shown above, the contribution of this phase varies from insignificant to $90 \%$ of the NRM intensity. Above these temperatures, one or two high temperature components have been found. For 
Table 1. Paleomagnetic Data for Igneous Rocks ${ }^{\mathrm{a}}$

\begin{tabular}{|c|c|c|c|c|c|c|c|c|c|c|}
\hline$\underline{\text { Station }}$ & $\mathrm{N}$ & $\mathrm{D}, \operatorname{deg}$ & $\mathrm{I}, \mathrm{deg}$ & $k$ & $\alpha_{95}, \operatorname{deg}$ & Geographic Coordinates & VGP $_{\text {Long, }}$ deg & $\mathrm{VGP}_{\text {Lat }}$, deg & $K$ & $A_{95}, \mathrm{deg}$ \\
\hline FZ1 & 6 & -26.6 & 40.1 & 183 & 4.2 & $30.12 \mathrm{~N}, 6.88 \mathrm{~W}$ & 252.4 & 65.2 & & \\
\hline FZ2 & 6 & -20.5 & 42.2 & 36 & 9.5 & $30.13 \mathrm{~N}, 6.57 \mathrm{~W}$ & 246.6 & 70.3 & & \\
\hline FZ7 & 17 & -21.8 & 43.8 & 58 & 4.4 & $30.35 \mathrm{~N}, 6.58 \mathrm{~W}$ & 254.9 & 70.2 & & \\
\hline FZ8 & 10 & -20.7 & 37.8 & 128 & 3.8 & $30.35 \mathrm{~N}, 6.58 \mathrm{~W}$ & 242.1 & 69.3 & & \\
\hline FZ9 & 10 & -28.8 & 41.0 & 113 & 4.2 & $30.37 \mathrm{~N}, 6.56 \mathrm{~W}$ & 255.4 & 63.5 & & \\
\hline FZ11 & 16 & -29.8 & 30.9 & 20 & 7.9 & $30.33 \mathrm{~N}, 6.57 \mathrm{~W}$ & 243.5 & 59.6 & & \\
\hline FZ12 & 13 & -23.1 & 40.2 & 105 & 3.8 & $30.71 \mathrm{~N}, 6.18 \mathrm{~W}$ & 248.6 & 68.0 & & \\
\hline Mean & 6 & 336.4 & 40.9 & 611 & 2.3 & paleomagnetic pole & 250.3 & 67.8 & 562 & 2.4 \\
\hline
\end{tabular}

${ }^{\mathrm{a}} \mathrm{N}$, total of analyzed samples; D and I, mean declination and inclination; $k$ and $K$, precision parameter; $\alpha_{95}$ and $A_{95}, 95 \%$ confidence limit of the mean direction; VGP, Virtual Geomagnetic Pole and paleomagnetic pole for the mean data.

some samples they have partially similar unblocking temperature spectra for temperatures below $500^{\circ} \mathrm{C}$, represented by a curve on the Zijderveld diagram. However, it is still possible to obtain paleomagnetic directions by least-squares straight line on part of the Zijderveld diagram for these samples. The mean direction of the highest temperature component for all the locations along the Foum Zguid dyke shows a NW declination with a positive inclination around $40^{\circ}$ (see Table 1 and Figure 4). In part of the samples of all sites, the intermediate temperature component has an orientation corresponding to that of the present day magnetic field. In the remaining samples, other orientations are observed. On the NW border of dyke B at FZ11, four samples yield a mean direction defined by $D$ (declination $)=214.5^{\circ}, I$ $($ inclination $)=9.6^{\circ}, k$ (precision parameter $)=64$ and $\alpha_{95}$ (radius of the angular confidence zone at $95 \%$ ) $=8.8^{\circ}$. A neighboring direction towards the SW has been obtained for one sample in sites FZ2 and FZ12. At FZ8, a direction defined by $D=320.1^{\circ}, I=58.3^{\circ}, k=229$ and $\alpha_{95}=4.1^{\circ}$ has been determined from 5 samples.

\section{Discussion and Conclusions}

\subsection{Contact Test Using Host Rocks}

[13] Silva et al. [2006] pointed out the presence of hematite and, probably, of Ti-poor titanomagnetite as the main magnetic carriers for the sedimentary rocks hosting the FZD. The evolution of magnetization intensity during thermal demagnetization procedures clearly confirms the presence of hematite everywhere in the sedimentary rocks.
Ti-poor titanomagnetite seems to be also present in group A samples close to the dyke at FZ8, and in groups A and B at FZ11. However, owing to the high proportion of remaining remanence after heating at $580^{\circ} \mathrm{C}$, this mineral is probably much less abundant than hematite. It was not found far from the dykes and its occurrence is therefore related to dyke intrusion. It could result from local transformation of a preexisting mineral, but it was more probably formed during metasomatic processes because it is the main magnetic mineral within the dykes themselves.

[14] A strong variation in hematite abundance among samples was observed. This variation clearly stands out when comparing the NRM intensity for samples at different distances from the dykes. The intensity close to the dyke is about twice at FZ8 and more than 350 times higher at FZ11 than for the samples the farthest from the dyke. These changes are also partially related to dyke thickness. The observed decrease in NRM intensity starts at $20 \mathrm{~m}$ away from the thick dyke (FZ8), and at $1 \mathrm{~m}$ or less away from the thinner dykes (FZ11).

[15] At FZ11, the ChRM has similar orientation in samples of groups A and B and in the dyke itself. For group $\mathrm{C}$, a magnetization component can be precisely defined for temperatures below 630 to $650^{\circ} \mathrm{C}$ according to the samples; a higher temperature component remains after heating at these temperatures but cannot be precisely determined. The component for lower temperature has relatively scattered directions around a direction not very far from that of the ChRM of groups A and B, which could indicate that this component results from superimposition
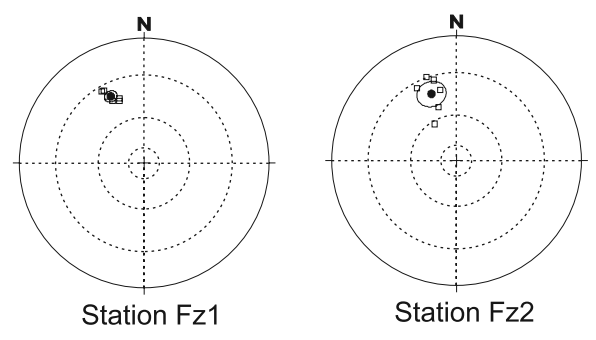

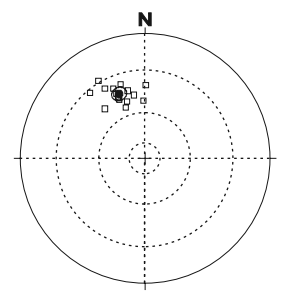

Station Fz7

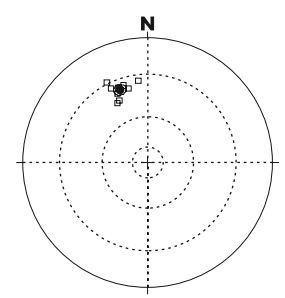

Station Fz8

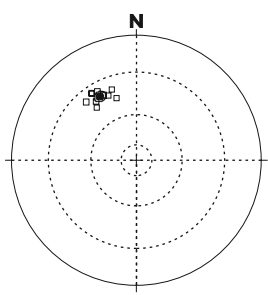

Station Fz9

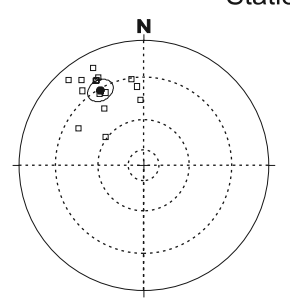

Station Fz11

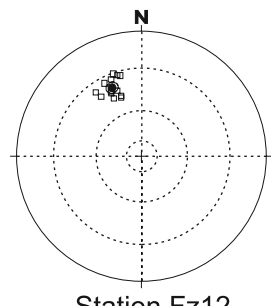

Station Fz12

Figure 4. Stereographic plots of the high-stability ChRM components (squares) and main directions (circles). 
with the highest temperature one [Bouabdallah et al., 2003], hence indicating a small effect of metasomatism even relatively far from the dyke. The magnetization direction in host-rocks here is different close to and far from the dykes, being quite similar to that of the dyke itself only when close to it. At FZ11, positive contact test indicates age of the magnetization within the dyke related with magma intrusion and cooling.

[16] Silva et al. [2006] showed that samples of group C at FZ11 did not experience thermal episodes with temperatures higher than $300^{\circ} \mathrm{C}$ after dyke emplacement. The temperature for group B at FZ11 was possibly higher, but certainly did not reach value as high as $670^{\circ} \mathrm{C}$. Overprinting thermoremanence cannot therefore explain a remagnetization isolated by thermal demagnetization up to this temperature in samples from group B. Similarly, if the component determined for temperatures lower than $630-650^{\circ} \mathrm{C}$ for group $\mathrm{C}$ can be partially related to intrusion, it cannot be explained by a thermal effect in these rocks heated at less than $300^{\circ} \mathrm{C}$. Consequently, remagnetization of host rocks due to intrusion is a Chemical Remanent Magnetization (CRM), at least partly. Thus, the obtained positive contact test in our case is mainly related to metasomatic processes. If a thermal effect exists, it is hidden at FZ11 by the CRM.

[17] At FZ8 the dyke is much thicker (ca.120m), hence the temperature reached in host-rocks was much higher. At this site, two factors present variation with distance to the dyke: the inclination of the ChRM and the relative proportion of the titanohematite phases with maximum blocking temperature around $610-620^{\circ} \mathrm{C}$ and between $650-670^{\circ} \mathrm{C}$. This suggests that the ChRM results from the superimposition of two components carried by these slightly different titanohematite phases, and that these components show partially superimposed spectra of blocking temperature [Bouabdallah et al., 2003]. We can remark that the component with maximum blocking temperature around $610-620^{\circ} \mathrm{C}$ seems to have a stable intensity independently of the distance to the dyke (the amount of NRM remaining above $620^{\circ} \mathrm{C}$ treatment roughly correlates with the NRM intensity). It could likely represent a component not related to the metasomatism, but it has orientation similar to that obtained within the dyke. It therefore corresponds to the thermal overprint. On the contrary, a clear relationship exists between intensity of the component with maximum blocking temperature around $650-670^{\circ} \mathrm{C}$ and distance to the dyke. In addition, this component almost disappears in the samples the farthest from the dyke. It is then in relation with the metasomatic processes. Its orientation is probably very close to that of the ChRM for host-rocks samples taken near the dyke (minimum contribution of the other component in the total magnetization). This orientation is slightly different from that obtained within the dyke and this component was then formed after intrusion. We noticed that Ti-poor titanomagnetite was not observed in this site, except very close to the dyke border. Silva et al. [2006] observed in host-rocks hematite grains probably resulting of oxidation of previous spinels. The component with maximum blocking temperature around $650-670^{\circ} \mathrm{C}$ could then be a CRM acquired by inversion to hematite of the Ti-poor titanomagnetite few after intrusion. But this can also simply indicate that, contrary to the case of thin dykes that have fast cooling, the metasomatic processes continued for a signifi- cant time after intrusion in the case of so huge dyke. AT FZ8, metasomatic processes are then very important for the remagnetization acquisition like at FZ11, but thermal magnetic overprint can be also pointed out.

\subsection{Dyke Paleomagnetic Data}

[18] Although Ti-poor titanomagnetite appears to be the main magnetic carrier for the igneous rocks, a result already shown by rock-magnetism studies [Silva et al., 2004], the presence of another magnetic phase could be identified for temperatures ranging between $280^{\circ} \mathrm{C}$ and ca. $480^{\circ} \mathrm{C}$ from the demagnetization procedures. This range of temperatures frequently superposes partially with the unblocking temperature spectra of titanomagnetite, promoting a curved shape at the Zijderveld diagram. Such magnetic phase could correspond to maghemite [O'Reilly, 1984; Dunlop and Özdemir, 1997].

[19] The low temperature component (usually lower than $280^{\circ} \mathrm{C}$ ) is probably a viscous magnetization. The origin of the intermediate temperature component is not clear. Partial superimposition of unblocking temperature spectra with the high temperature component shows that it cannot be only a Thermo-Remanent Magnetization (TRM). No indication of lightening effects has been found, and the intermediate component therefore corresponds to a CRM. From petrographic analyses, Silva et al. [2004] found evidences of moderate oxidation of magnetite within many grains, which could justify the presence of maghemite as a probable product responsible for the CRM [Dunlop and Özdemir, 1997]. Such oxidation in magmatic intrusions often occurs during late magmatic phases or post-magmatic hydrothermal events. This could explain the intermediate temperature directions different from the recent field in sites FZ2, FZ8, FZ11 and FZ12. The directions close to the recent field likely correspond to widespread CRM acquired since Upper Tertiary times in the Saharan region [Henry et al., 2004].

[20] The ChRM leads to an excellent definition of the mean site directions, with high values for the precision parameter $(k)$ and small angular confidence zone (mostly $\alpha_{95}<5^{\circ}$ ). The sites corresponding to the main dyke have a mean direction defined by $D=336.4^{\circ}$ and $I=40.9^{\circ}$, with $k=611$ and $\alpha_{95}=2.3^{\circ}$ (Table 1). The samples from the thinner dykes at FZ11 yield a direction slightly different from that of the main dyke. This result could correspond to a slightly different age of magnetization. The FZ11 paleomagnetic data were therefore not included in the determination of our mean pole. Recently, a detailed paleomagnetic study of the FZD Palencia-Ortas [2004] yielded a paleomagnetic pole $\left(247.9^{\circ} \mathrm{E}, 67.9^{\circ} \mathrm{N}\right)$ significantly different from the pole $\left(259.0^{\circ} \mathrm{E}, 58.0^{\circ} \mathrm{N}\right)$ of Hailwood and Mitchell [1971] which was determined applying only partial demagnetization. The pole obtained from our group of samples (Table 1) confirms the Palencia-Ortas [2004] results and is also similar to the paleomagnetic pole $\left(241.3^{\circ} \mathrm{E}, 73.0^{\circ} \mathrm{N}\right)$ determined by Knight et al. [2004] for similar age lava flows from Morocco High Atlas, and to that $\left(244.6^{\circ} \mathrm{E}, 63.9^{\circ} \mathrm{N}\right)$ of Besse and Courtillot [2002] for Africa at 198.9 Ma. From the results of the present work it is possible to conclude that at least in the case of the Foum Zguid Dyke, the positive contact test is mainly related to Fe-metasomatism in the host sedimentary rocks during magma intrusion and cooling. The paleomagnetic pole 
obtained by Palencia-Ortas [2004] is therefore related to the Earth magnetic field during intrusion and can be considered as a well-constrained paleomagnetic pole for Africa $197 \mathrm{Ma}$ ago.

[21] Acknowledgments. Funding by TEAMINT (POCTI/CTE/ 48137/2002), CNRS - France, GRICES - Portugal and Gulbenkian Foundation is acknowledged. We thank Maxime Le Goff for technical assistance during experimental work and C. Catita, N. Lourenço, A. Palencia, R. Vegas, A. Touil and A. Hafid for field assistance.

\section{References}

Aarab, E. M., A. Rahimi, and G. Rocci (1994), Un exemple de différenciation transverse: le Grand Dyke de Foum Zguid (Anti-Atlas, Maroc), C.R. Acad. Sci. Paris, Ser. II, 319, 209-215.

Besse, J., and V. Courtillot (2002), Apparent and true polar wander and the geometry of the geomagnetic field over the last $200 \mathrm{Myr}, J$. Geophys. Res., 107(B11), 2300, doi:10.1029/2000JB000050.

Bouabdallah, H., B. Henry, N. E. Merabet, and S. Maouche (2003), Juxtaposed and superimposed magnetizations in Carboniferous formations of the Tindouf basin, Bull. Serv. Geol. Algerie, 14, 53-64.

Butler, R. (Ed.) (1992), Paleomagnetism: Magnetic Domains to Geologic Terranes, 250 pp., Blackwell Sci., Malden, Mass.

Dunlop, D. J. and Ö. Özdemir (Eds.) (1997), Rock Magnetism: Fundamentals and Frontiers, 573 pp., Cambridge Univ. Press, New York.

Fisher, R. A. (1953), Dispersion on a sphere, Proc. R. Soc. London, Ser. A, $217,98-102$.

Hailwood, E. A., and J. G. Mitchell (1971), Paleomagnetic and radiometric dating results from Jurassic intrusions in South Morocco, Geophys. J. R. Astron. Soc., 24, 351-364.

Henry, B., N. E. Merabet, M. E. M. Derder, and B. Bayou (2004), Chemical remagnetizations in the Illizi basin (Algeria), Geophys. J. Int., 156, 200212.

Kirschvink, J. L. (1980), The least squares line and plane and the analysis of paleomagnetic data, Geophys. J. R. Astron. Soc., 62, 699-718.

Knight, K. B., S. Nomade, P. R. Renne, A. Marzoli, H. Bertrand, and N. Youbim (2004), The Central Atlantic Magmatic Province at the Triassic-Jurassic boundary: Paleomagnetic and 40Ar/39Ar evidence from Morocco for brief, episodic volcanism, Earth Planet. Sci. Lett., 228, 143-160.

Leblanc, M. M. (1974), Le grand dyke de dolerite de l'Anti-Atlas et le magmatisme jurassique du Sud marocain, C.R. Acad. Sci. Paris, Ser. D, $276,2943-2946$.

Marcais, J., and G. Choubert (1956), Les Grands Traits de la Géologie du Maroc, Lexique Stratigraphique du Maroc, Introduction Géologique, Serv. Géol. du Maroc, Rabat.

May, P. R. (1971), Pattern of Triassic-Jurassic diabase dikes around the North Atlantic in the context of predrift position of the continents, Geol. Soc. Am. Bull., 82, 1285-1292.

McFadden, P. L., and M. W. McElhinny (1990), Classification of the reversal tests in paleomagnetism, Geophys. J. Int., 103, 725-729.

O'Reilly, W. (Ed.) (1984), Rock and Mineral Magnetism, 220 pp., CRC Press, Boca Raton, Fla.

Palencia-Ortas, A. (2004), Estudio Paleomagnético de rocas de edad Jurásica de La Península Ibérica y sur de Marruecos, Ph.D Thesis, Universidad Complutense de Madrid, ISBN: 84-669-2865-0.

Sebai, A., G. Feraud, H. Bertrand, and J. Hanes (1991), 40Ar/39Ar dating and geochemistry of tholeiitic magmatism related to the early opening of the Central Atlantic rift, Earth Planet. Sci. Lett., 104, 455-472.

Silva, P. F., F. O. Marques, B. Henry, A. Mateus, N. Lourenço, and J. M. Miranda (2004), Preliminary results of a study of magnetic properties in the Foum-Zguid dyke (Morocco), Phys. Chem. Earth, 29, 909-920.

Silva, P. F., B. Henry, F. O. Marques, A. Mateus, P. Madureira, N. Lourenco, and J. M. Miranda (2006), Variation of magnetic properties in sedimentary rocks hosting the Foum Zguid dyke (Southern Morocco): Combined effects of re-crystallization and Fe-metasomatism, Earth Planet. Sci. Lett., $241,978-992$.

B. Henry, Paleomagnetism, IPGP and CNRS, 4 av. de Neptune, F-94107 Saint-Maur cedex, France.

P. Madureira, CGE, Universidade de Évora, R. Romão Ramalho, 59, 7000-671 Évora, Portugal.

F. O. Marques and J. M. Miranda, IDL, Universidade de Lisboa, Campo Grande, 1749-016 Lisboa, Portugal.

P. F. Silva, DEC, Instituto Superior Engenharia Lisboa, R. Cons. Emídio Navarro, 1, 1950-062 Lisboa, Portugal. (pmfsilva@fc.ul.pt) 